\title{
ANÁLISE DAS CALÇADAS NA CIDADE DE TEÓFILO OTONI/MG: ESTUDO DE CASO DA ÁREA DE ACESSO A UNIVERSIDADE PRESIDENTE ANTÔNIO CARLOS
}

\section{ANALYSIS OF SIDEWALKS IN THE CITY OF TEÓFILO OTONI / MG: STUDY OF CASE OF THE UNIVERSITY ACCESS AREA PRESIDENT ANTÔNIO CARLOS}

\author{
Felipe Camargo Silva Cardoso, \\ Acadêmico do $10^{\circ}$ período do Curso de Engenharia Civil da Faculdade Presidente \\ Antônio Carlos de Teófilo Otoni, Brasil. \\ E-mail: felipecross54@yahoo.com.br
}

Franco Pereira Machado, Acadêmico do 10ำ período do Curso de Engenharia Civil da Faculdade Presidente Antônio Carlos de Teófilo Otoni, Brasil. E-mail:francopmachado@bol.com.br

Danilo Carvalho Miranda, Bacharel em Administração, Especialista em Gestão de Negócios e Finanças, Professor do Curso de Engenharia Civil da Faculdade Presidente Antônio Carlos de Teófilo Otoni, Brasil. E-mail:danilocarvalho.unipacto@hotmail.com

\section{Resumo}

Este trabalho tem como principal foco a análise das calçadas da cidade de Teófilo Otoni/MG que dão acesso a Universidade Presidente Antônio Carlos (UNIPAC). A má qualidade dos materiais e métodos na execução dos passeios apresentam uma série de patologias que comprometem na qualidade, estabilidade e segurança da obra e dos indivíduos. A pesquisa foi elaborada da seguinte forma: identificação do local, análise e relatório patológico e por fim, as possíveis soluções para o problema. Os resultados poderão ser usados para o desenvolvimento de um planejamento de políticas urbanas, buscando a acessibilidade e mobilidade sustentável das calçadas.

Palavras-chave: Patologia; Acessibilidade; Mobilidade; Planejamento; Calçadas.

\section{Abstract}

This work has as main focus the analysis of the sidewalks of the city of Teófilo Otoni/MG that give access to The President Antônio Carlos University (UNIPAC). 
The poor quality of materials and methods in the execution of the tours present a series of pathologies that compromise on the quality, stability and safety of the work and individuals. The research was elaborated as follows: site identification, analysis and pathological report and, finally, possible solutions to the problem. The results can be used for the development of urban policy planning, seeking accessibility and sustainable sidewalks mobility.

Keywords: Pathology; Accessibility; Mobility; Planning; Sidewalks.

\section{Introdução}

A engenharia civil é um componente primordial para economia global e para a sociedade em geral. Por meio dela que se tem casas, cidades e uma vida em sociedade, se não fossem os recursos aplicados na construção civil os seres humanos seriam apenas um bando de neandertais vivendo em tribos - sem densidade o bastante para serem chamadas de cidades. A engenharia não é apenas voltada para as grandes construções como prédios, pontes e rodovias, ela também tem um papel primordial em contribuir de forma criativa e sustentável na vida social.

A mobilidade e a acessibilidade urbana tem sido um grande problema nos centros urbanos, ocasionado pela falta de planejamento urbano e da orientação das pessoas. Assim, podemos afirmar que a mobilidade e a acessibilidade em um contexto urbano e sustentável são condições básicas para toda e qualquer pessoa transitar na cidade, independentemente se ela for deficiente, idosa, gestante ou jovem, atendendo a todos de forma única.

A calçada é destinada ao pedestre, ou seja, aquele que realiza os deslocamentos a pé, seja para o trabalho, escola, lazer ou outras finalidades. Além disso, elas devem sempre estar em boas condições, com conforto, segurança, livre de obstáculos ou desníveis irregulares, promovendo o acesso universal para que todos possam usufruir, desde que não apresente dificuldades para a sua circulação.

"Além do tratamento adequado das calçadas, o planejamento da circulação
geral da cidade precisa contemplar a prioridade aos pedestres,
principalmente nas situações de confronto com os veículos motorizados. A
adoção de uma política de mobilidade para a construção de uma cidade
sustentável começa no processo de planejamento e de construção da
infraestrutura viária, utilizando recursos como: separação fíca da
circulação dos veículos das pessoas, construção de passarelas e 
passagens subterrâneas, implantação de calçadões e áreas de circulação restrita aos pedestres" (ARAUJO, 2019).

Devido ao processo acelerado de urbanização desgovernada e desprovida de um planejamento integrado entre as políticas de desenvolvimento urbano, transporte e mobilidade, muitos conflitos são observados nos centros urbanos.

Pode-se perceber que os problemas referentes a mobilidade é algo multidimensional que vão além do acesso aos meios de transporte, podendo citar entre outros: a precariedade da infraestrutura urbana, insuficiência dos equipamentos de serviços, apropriação ilegal do espaço de circulação, a falta de planejamento e organização dos passeios e a ausência de arborização e sinalização.

Todo empreendimento está suscetível a problemas no decorrer da sua vida útil, onde não apresenta o seu desempenho previsto, este fator é conhecido como patologia. Geralmente os problemas ocorrem devido à falta de investimentos, qualidade e a impunidade aos responsáveis pela construção. Segundo Thomaz (2001) apud Ueda (2017), o aparecimento de patologias decorre da inobservância, negligência, agentes agressivos ou até a falta de conhecimento e técnica de edificar.

Umas das alternativas mais eficazes e eficientes a serem testificadas são a reorganização e padronização universal das vias, de modo que elas possam cumprir com as suas funções.

\section{Objetivos}

Visando contextualizar esta problemática à realidade da maioria das calçadas da cidade de Teófilo Otoni-MG, foi oportunizado um estudo sistemático acerca do tema através de uma pesquisa de campo. Com isso, foi possível traçar um plano para compreender e minorar os problemas daquele passeio, tornando-o transitável, sustentável e confortável para os pedestres.

Além disso, o trabalho irá apresentar um diagnostico geral do problema e analisará as necessidades da população que transita pela região, utilizando essas dificuldades para propor as possíveis soluções para uma calçada sustentável com conforto, fluidez e segurança. 


\section{Metodologia}

Foi adotado para a realização do trabalho estudos de revisão bibliográfica, além de um levantamento estatístico de possíveis problemas encontrados nas calçadas da R. Eng. Célso Murta e da R. Antônio Onófre, bairro Olga Prates em Teófilo Otoni-Mg, onde será feito uma análise do local e uma pesquisa em campo por pedestres, estudantes e moradores da região.

Através desses dados fornecidos, podemos expor todos os componentes positivos e negativos das calçadas analisadas com os devidos graus de importância e riscos que são causados aos pedestres, bem como as possíveis soluções para o problema.

\section{Revisão da literatura}

\subsection{Contexto histórico}

As primeiras cidades surgiram em função das atividades da população presente no local, podemos dizer que foi através de um processo de urbanização e mobilidade. Os indivíduos buscavam por áreas com condições favoráveis para o seu sustento, com proposito de comercializar os seus bens e produtos (SANTANA, 2014; CORTESE, KNIESS, MACCARI, 2017; apud SANTOS, 2019).

O desenvolvimento de um desenho universal, conceito criado por uma comissão em Washington nos Estados Unidos em 1963, tem como foco principal a adequação e eliminação de impedimentos arquitetônicos e de equipamentos em áreas urbanas, promovendo a garantia de acessibilidade a todas as pessoas, respeitando as diferenças de cada um (CARLETTO e CAMBIAGHI, 2008).

A política de desenvolvimento urbano, tendo como base a Constituição Federal de 1988, expressa que a responsabilidade de desenvolver essas políticas compete ao município. O planejamento deve ordenar e o pleno desenvolvimento das funções socies da cidade, garantindo a segurança e o conforto das pessoas que nela transitam. No entanto, com a criação do Estatuto das Cidades (Lei Federal № 10.257 de 2001) o desenvolvimento das políticas urbanas começou e ter mais força, 
mesmo que ainda este assunto não seja tão debatido e eficiente na maioria das cidades brasileiras.

Outro marco importante foi a criação da Política Nacional de Mobilidade Urbana (Lei Federal № 12.587 de 2012), incorporando conceitos e assuntos mais abrangentes.

\footnotetext{
"A Política Nacional de Mobilidade Urbana tem por objetivo contribuir para o acesso universal à cidade, o fomento e a concretização das condições que contribuam para a efetivação dos princípios, objetivos e diretrizes da política de desenvolvimento urbano, por meio do planejamento e da gestão democrática do Sistema Nacional de Mobilidade Urbana" (BRASIL, 2012, Art. 2).
}

De acordo Almeida e Oliveira (2019), atualmente no Brasil, as políticas de mobilidade urbana tem focado nos automóveis particulares que tiveram um aumento de cerca de $400 \%$ na frota. Com isso, tem visto que os pedestres têm sofrido exclusões no sistema de locomoção nas cidades, problema que ocorre na prática, mas nas normas e legislações vigentes o foco está na categoria deles.

\subsection{Infraestrutura urbana}

Devido ao grande aumento da população, além do intenso fluxo de turistas e pessoas que vão para os grandes centros em busca de novas oportunidades ou acesso a uma variedade de serviços e atividades econômicas, a cidade nem sempre consegue acompanhar esse ritmo. O aumento do número de habitantes provoca um grande impacto na infraestrutura, nos sistemas: viário, acessibilidade e mobilidade, abastecimento de água, esgoto e drenagem, energia e comunicações, entre outros (PUPPI, 1981 apud NÓBREGA et al.).

\footnotetext{
"A infraestrutura geral da cidade é também um fator de relevância ímpar para o turista em visita ao destino em razão dos transtornos que a ausência ou falha em aspectos relacionados a este fator pode causar a viagem do turista. Embora se reconheça que a infraestrutura não seja um fator de atratividade em si, como uma praia, um monumento, um evento, um aspecto cultural ou uma paisagem única, entre outros, se observa que caso este apresente algum problema crítico pode afetar toda a percepção da qualidade do destino turístico, e acabar, assim, por prejudicar toda viagem" (Chagas, 2010, p.165 apud Vieira e Morastoni, 2013).
} 
Segundo Klein (1999) apud Ueda (2017), a má qualidade da execução nas obras favorece o surgimento de patologias, tanto em relação aos materiais utilizados, como as técnicas e habilidades da equipe. Toda construção necessita de um controle de qualidade rigoroso e experiente, buscando compreender os agentes físicos, químicos, biológicos e humanos que podem causar problemas presentes e futuros. A busca pela execução de boa qualidade garante a segurança da edificação e o crédito para os responsáveis pelo desenvolvimento da obra, ganhando confiança e referência no mercado.

Assim, podemos afirmar que o crescimento populacional é capaz de influenciar de forma direta com a qualidade de vida dos moradores. A responsabilidade em para suprir e amenizar os problemas da população compete ao governo, que deve além de fiscalizar, realizar melhorias e ampliações nos sistemas de infraestrutura, mobilidade e acessibilidade.

\subsection{Mobilidade urbana sustentável}

O crescimento e desenvolvimento dos centros urbanos devem acontecer de forma planejada e sustentável, observando a área como um todo, além de analisar os diferentes sistemas viários e os polos geradores de viagens. Para isso é necessário que o poder público desenvolva as suas políticas urbanas, como o Plano Diretor Municipal (PDM), utilizando uma visão sistemática e analítica do município com o apoio dos comerciantes e da população local.

Segundo Mendes e Fantin (2012) apud Santos (2019), em relação a mobilidade urbana, podemos destacar que ela é influenciada pela expansão da cidade e o aumento da população. Esse crescimento pode gerar consequências nos centros urbanos, tais como o congestionamento das vias, poluição sonora e do ar, estresse, acidentes, perda de tempo e outros.

De acordo com o Código de Trânsito Brasileiro (CTB, 1997), as calçadas são locais destinados a pedestres e cadeirantes, tendo como objetivo proporcionar a segurança, conforto e acessibilidade para as pessoas, separando-os das áreas 
transitáveis por veículos, além de ser o local adequado para os pedestres deslocarem entre os bairros da cidade.

\footnotetext{
"É assegurada ao pedestre a utilização dos passeios ou passagens apropriadas das vias urbanas e dos acostamentos das vias rurais para circulação, podendo a autoridade competente permitir a utilização de parte da calçada para outros fins, desde que não seja prejudicial ao fluxo de pedestres" (BRASIL, 1997, Art. 68).
}

A mobilidade urbana sustentável pode ser vista como uma maneira de promover a diminuição do uso de automóveis privados por meios alternativos que facilitem o acesso da população às atividades físicas ou a meios coletivos. Vale ressaltar que o principal elemento do meio sustentável é o pedestre, sendo que a ele deve ser garantido a segurança, acesso e facilidade para realizar os deslocamentos.

Segundo o Manual da Calçada Sustentável (MCS, 2012), os passeios devem apresentar três elementos essenciais, são elas as faixas de serviços, livre e de acesso. As faixas de serviços são destinadas para os equipamentos e mobiliários urbanos, ou seja, árvores, lixeiras, hidrantes, postes, placas de sinalização, rebaixos para acessos de pessoas e para veículos e outros. As faixas livres são destinadas exclusivamente para a locomoção de pedestres, para isso elas devem apresentar segurança, conforto e ausência de interferências ou obstáculos. Já a faixa de acesso é destinada ao imóvel, devendo respeitar as demais.

É necessário que o poder público desenvolva e implemente índices para avaliar a qualidade dos espaços públicos, buscando regularizar e criar os locais destinados aos pedestres, além de identificar os trechos de possíveis riscos de acidentes. Devido ao aumento na frota de veículos particulares, as cidades começaram a focar em vias e acessos aos automóveis, deixando de priorizar os pedestres.

\section{Estudo de caso}

\subsection{Análise do local de estudo}

O levantamento em campo do trecho analisado, composto por quatro ruas, referente 
a quadra que está localizada a Universidade Presidente Antônio Carlos na cidade de Teófilo Otoni, Minas Gerais. As situações mais críticas estão nas ruas: Engenheiro Celso Murta e a Antônio Onófre. A área possui diversos polos geradores de viagens que apresentam grande fluxo de pessoas e veículos para acessarem as atividades, sendo que a rua Engenheiro Celso Murta apresenta a maior quantidades destes polos. Nesta rua podemos citar o Container`s Happy Hour, a Escola Estadual Doutor Felipe Moreira Caldas, o Colégio Genoma, o Departamento Nacional de Infraestrutura de Transportes (DNIT), a Universidade Presidente Antônio Carlos (UNIPAC) e outros pontos de movimentações constantes.

Nos dois trechos citados é possível observar a falta de pavimentação e inexistência de calçadas, obstáculos que prejudicam a circulação (entulhos, vegetação, desníveis, buracos, pedras soltas e outros), além do posicionamento irregular do imóvel urbano.

$\mathrm{Na}$ foto 1 pode ser observado a inexistência de calçadas do lado esquerdo, o pedestre é forçado a transitar na via ou a atravessar para o outro lado da rua para utilizar a calçada que também não apresenta condições adequadas para utiliza-la, além disso, é possível ver que há um pequena área reservada para uma possível calçada que apresenta vegetação em toda a sua extensão.

Foto 1 _ Vista da R. Antônio Onófre

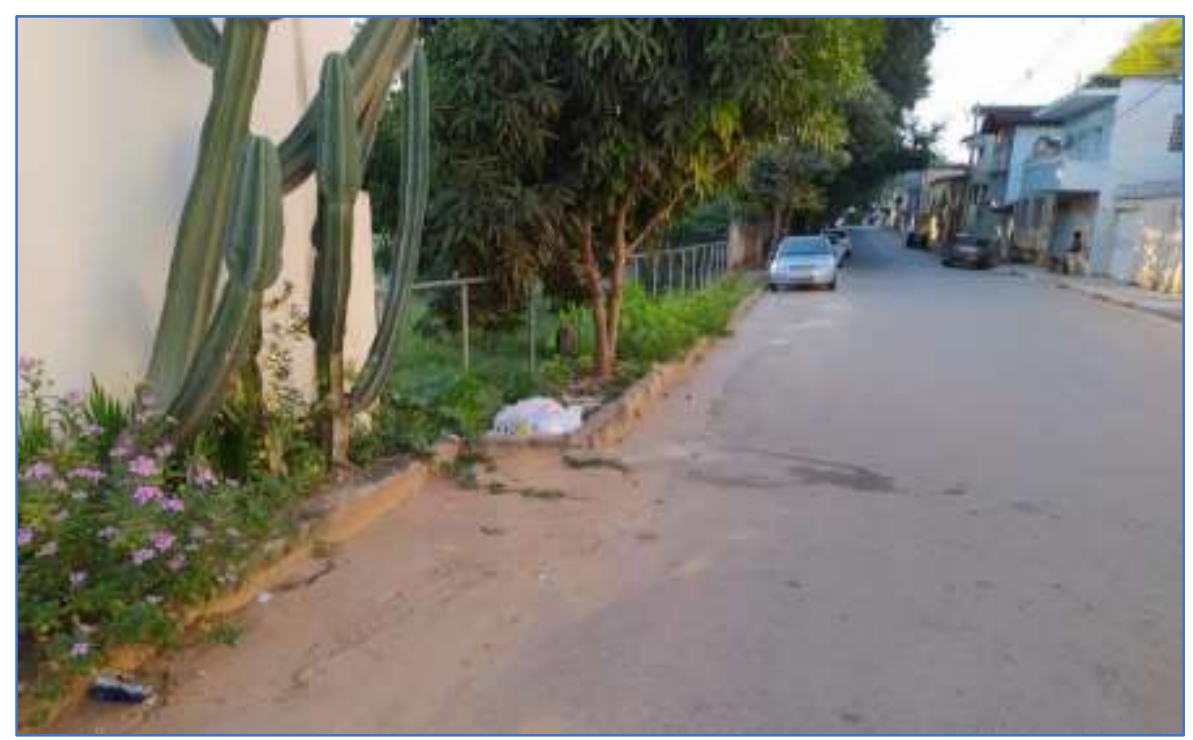

Fonte: Autoria própria 
Ainda na mesma rua, é possível ver na foto 2 que os moradores deste trecho descarregaram entulhos na calçada, desta maneira o caminho está obstruído por rejeitos. O poder público municipal deve fiscalizar, orientar e punir a população para utilizarem os meios corretos de destinação de entulhos, evitando que o local apresente riscos de acidentes, alagamentos, proliferação de roedores e insetos causadores de doenças.

Foto 2 _ Vista da R. Antônio Onófre

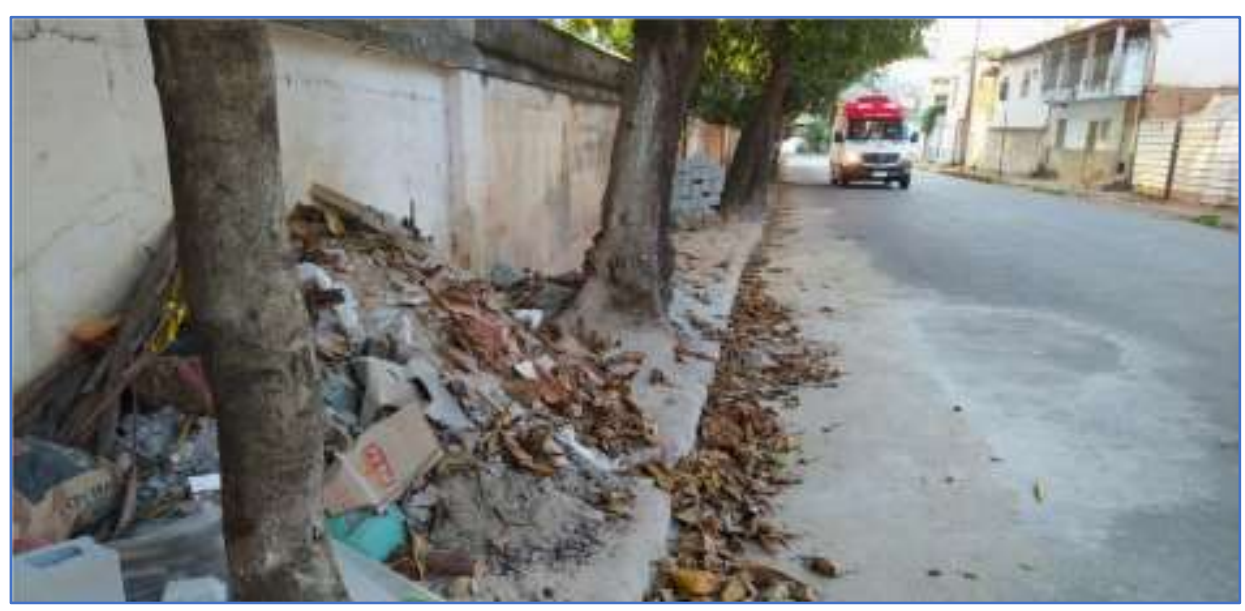

Fonte: Autoria própria

Outro problema observado na R. Antônio Onófre é a destruição da calçada e da via devido a vegetação local, foto 3, pois o trecho não apresenta espaço e nem manutenção para o recebimento e desenvolvimento das árvores. O local apresenta grande quantidade de árvores, sendo necessário a limpeza constante das folhas para evitar o risco de alagamento da rua (fato que ocorre com frequência no local, segundo os dados do município e relatos dos moradores). 
Foto 3 - Vista da R. Antônio Onófre

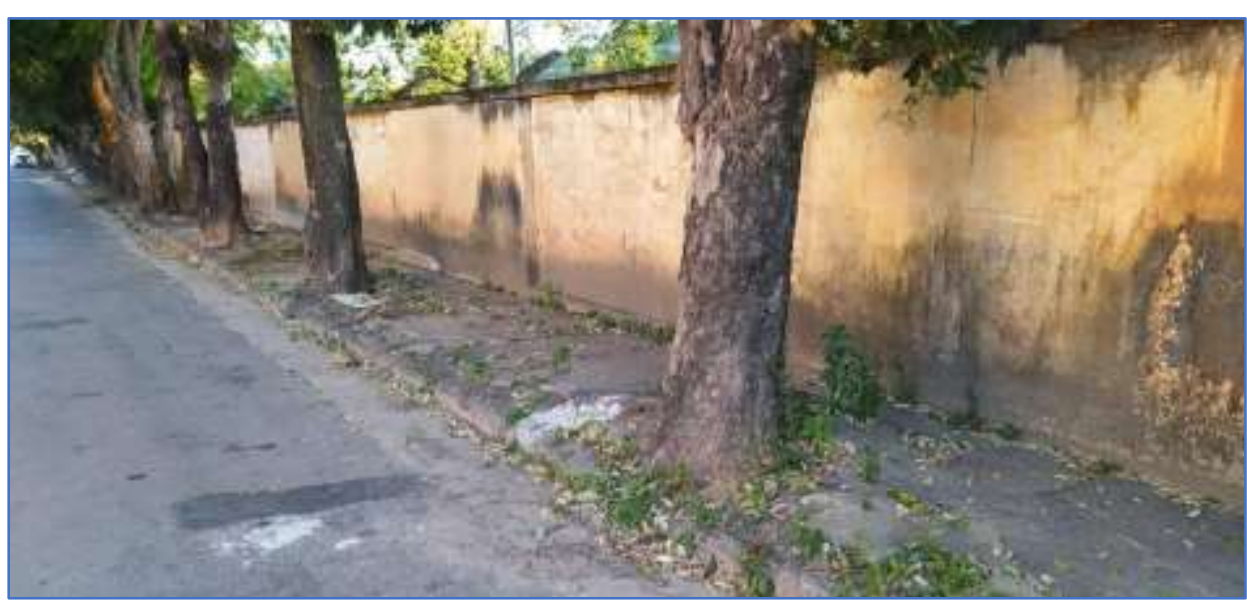

Fonte: Autoria própria

Dentre vários problemas observados nas calçadas, um dos mais recorrentes é o desgaste e a falta de manutenção, além de não apresentar segurança ou conforto para os usuários. Na R. Eng. Célso Murta, foto 4, podemos perceber claramente que - passeio apresenta vários problemas para os seus usuários. Devido as características do trecho é possível concluir que um dos maiores agentes causadores desta falha foi a drenagem da via. 
Foto 4 - Vista da R. Engenheiro Celso Murta

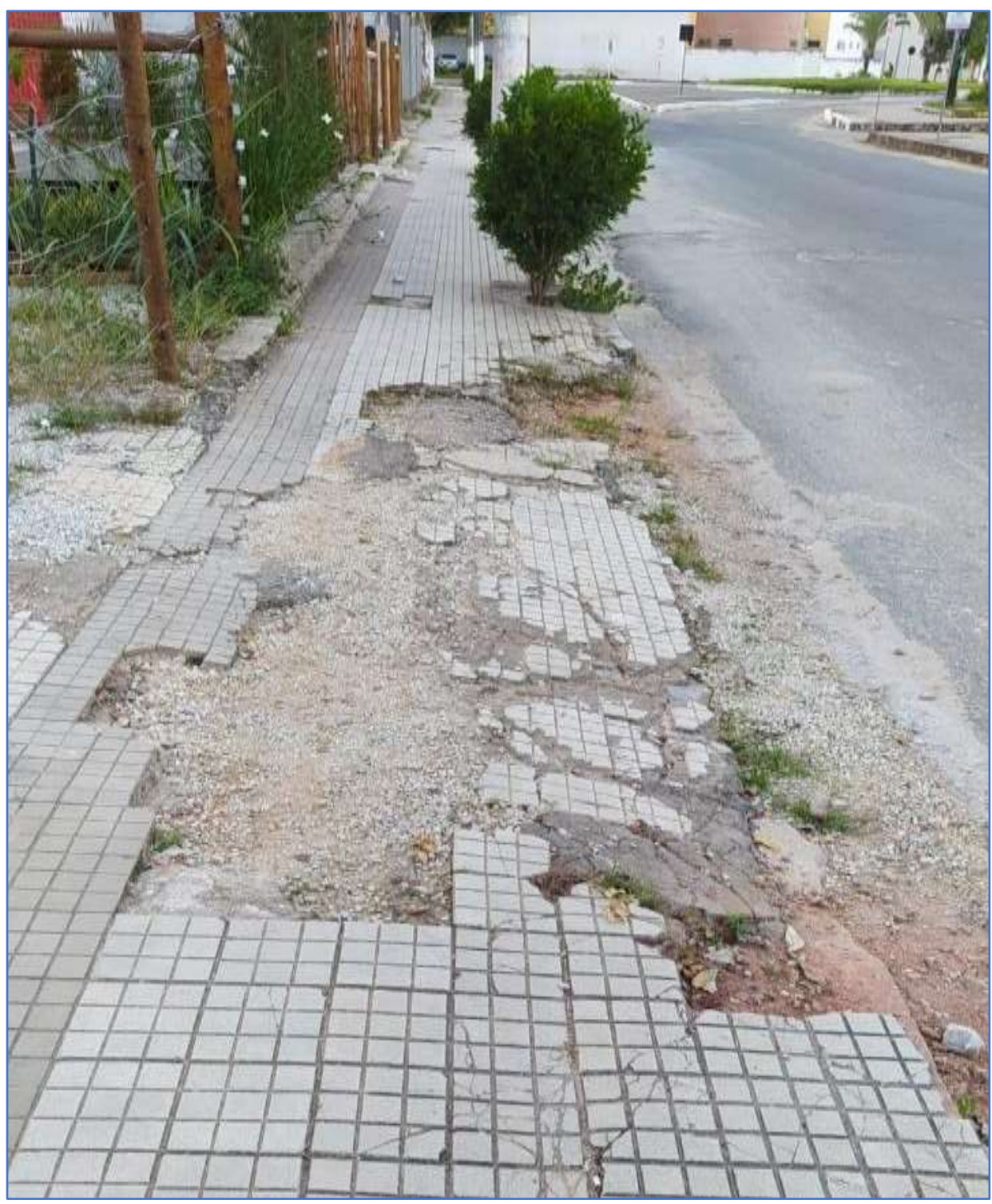

Fonte: Autoria própria

Pode-se notar na foto 5 que a calçada aparentemente não apresenta dificuldades para locomoção, entretanto no trecho a calçada está com rachaduras devido as raízes das árvores e há pontos preenchidos com concreto (remendos devido a perda dos ladrilhos). 
Foto 5 - Vista da R. Engenheiro Celso Murta

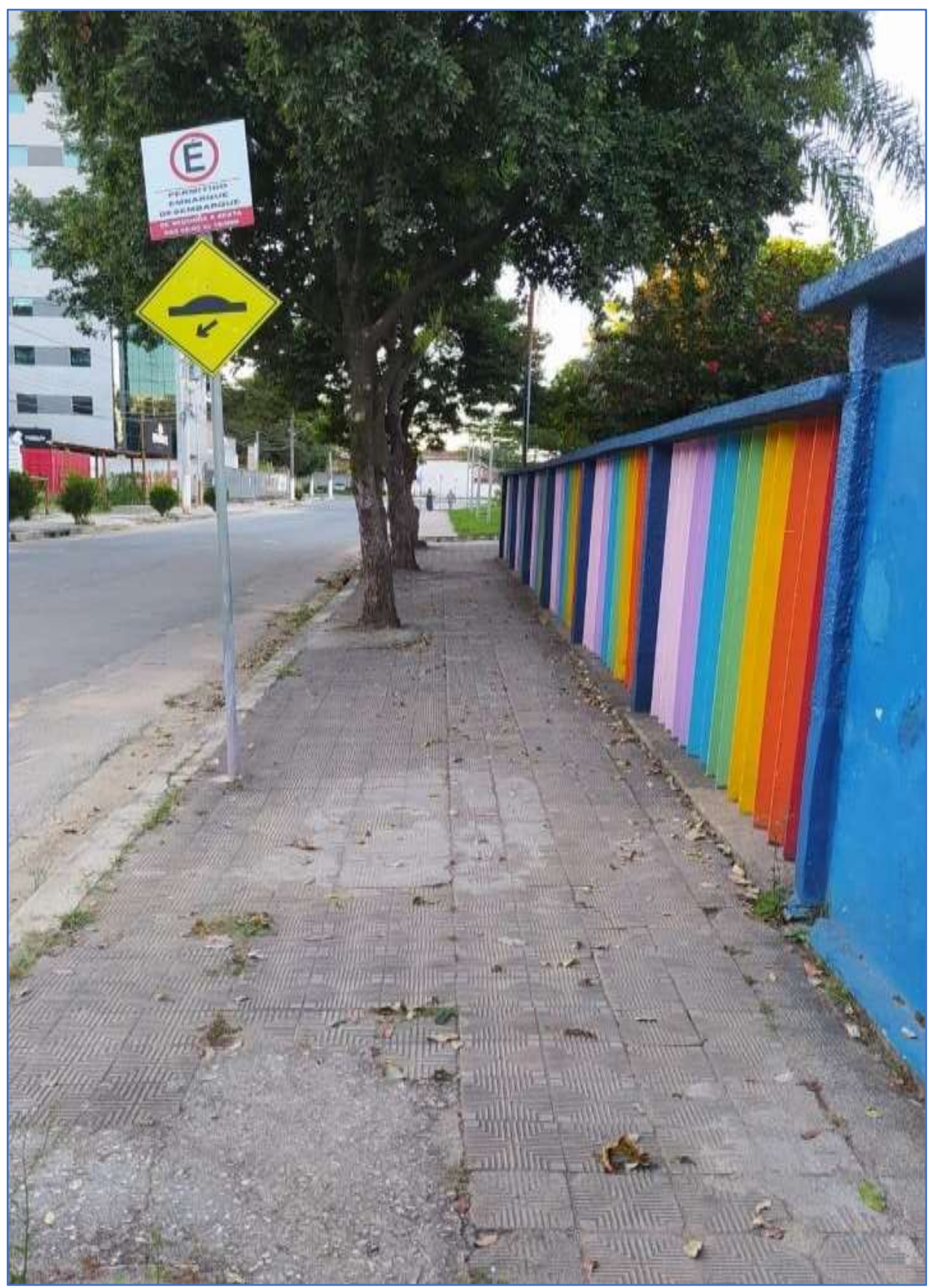

Fonte: Autoria própria

$\mathrm{Na}$ foto 6 observa-se que há desníveis e irregularidades no piso, por conseguinte as pessoas com mobilidade reduzida ou deficientes terão maiores dificuldades para transitarem por este local. Já na foto 7 podemos ver que o tronco da árvore ocupa mais da metade do espaço de circulação, além disso, a calçada apresenta rachaduras ao redor da árvore, defeito causado por sua raiz. Outro problema nesta 
foto é a altura da calçada, neste trecho ela possui dimensões acima do máximo exigido em norma.

Foto 6 _ Vista da R. Engenheiro Celso Murta

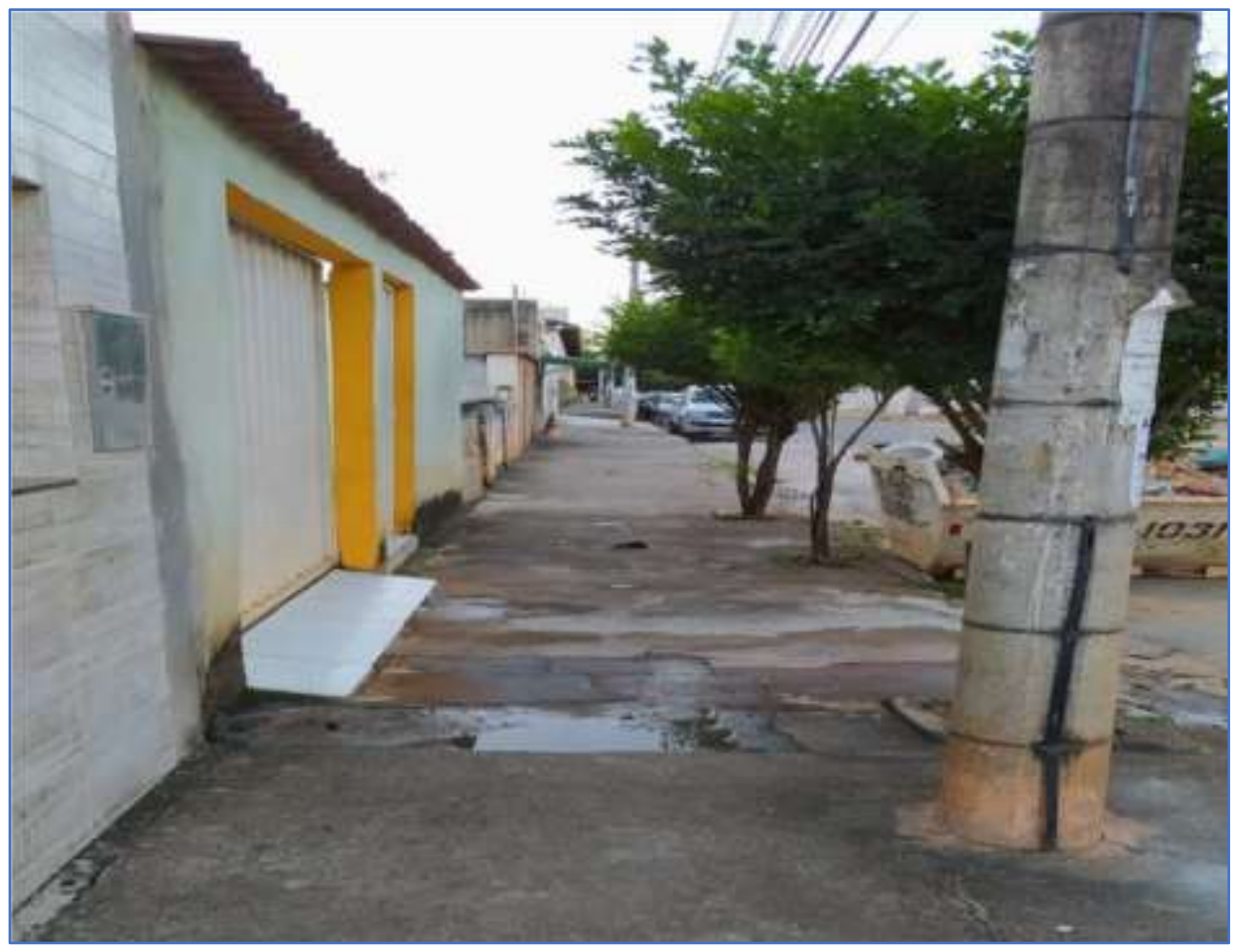

Fonte: Autoria própria 
Foto 7 _ Vista da R. Engenheiro Celso Murta

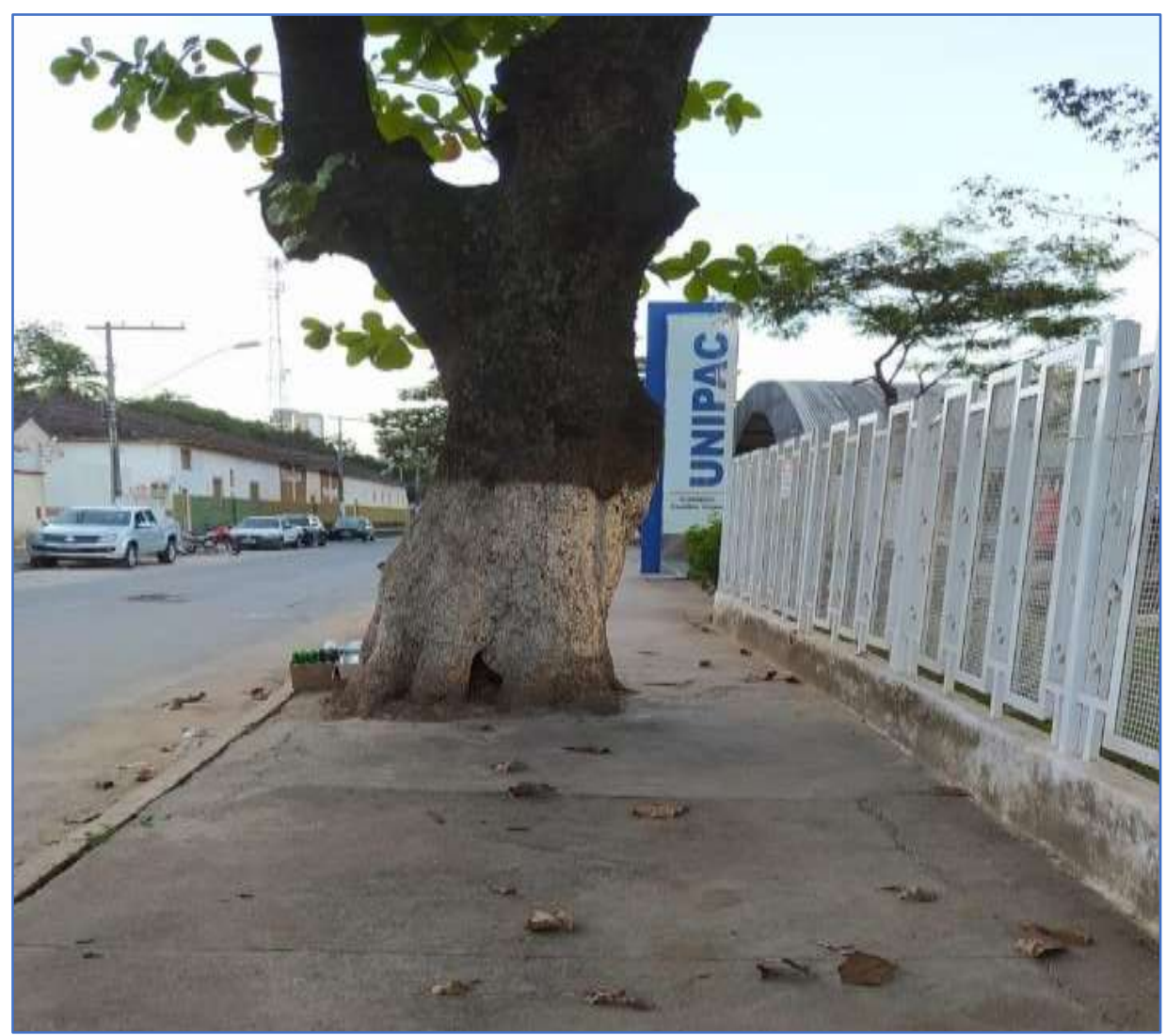

Fonte: Autoria própria

Por fim, na foto 8 o trecho apresenta uma calçada inacabada que segundo os moradores e estudantes, o segmento não possui drenagem (a água fica empossada no passeio, forçando as pessoas a transitarem pela via para desviarem das possas), além disso o local possui desníveis, rachaduras causadas pelas raizes e pontos que estão exatamente no solo. 
Foto 8 - Vista da R. Engenheiro Celso Murta

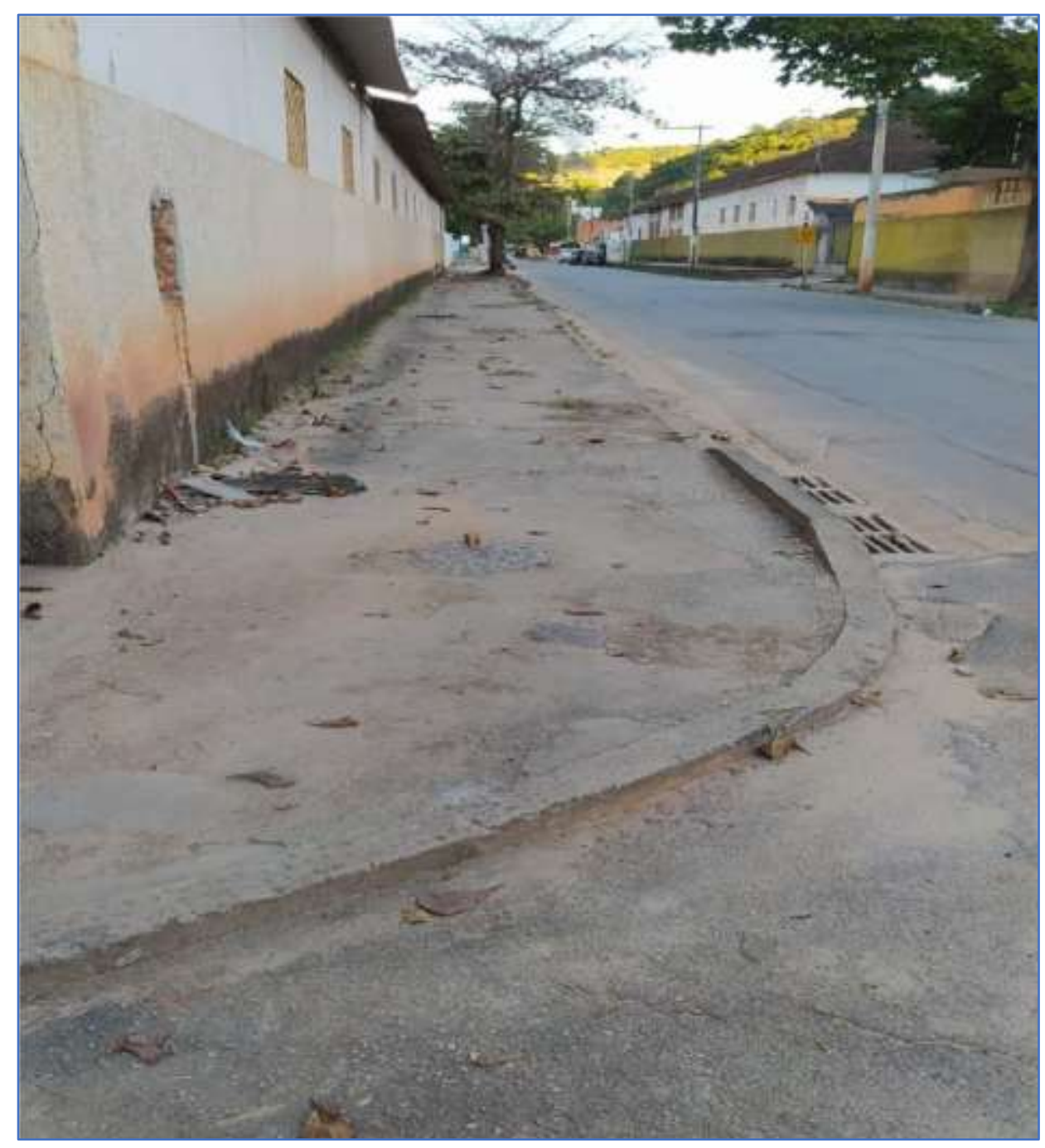

Fonte: Autoria própria

Observando-se as fotos acima, além dos problemas apresentados sobre as calçadas,

pode-se perceber que os locais utilizam revestimentos diferentes, tais como: concreto comum, placas de concreto e ladrilho. Esse tipo de pavimentação possui baixa impermeabilização do solo e aumento do volume de escoamento de água e baixa. Em relação a manutenção deste segmento, caso seja necessário a substituição ou troca de uma determinada parte do trecho, haverá remendos que geram irregularidades e dificuldades na locomoção das pessoas, sendo considerado também como uma nova patologia. 
Outro problema observado está relacionado com o rebaixo de meio fio para garantir a acessibilidade das pessoas que dela necessitam, é notório observa que isto é praticamente inexistente, além disso, não apresentam sinalização adequada para os usuários. Nos relatos fotográficos anteriores é possível observar a variação de desníveis e irregularidades, assim, muitas pessoas preferem transitar na via em vez de utilizar a calçada.

No intuito de economizar, por falta de verba ou negligencia do responsável pela obra, os passeios das duas ruas estudadas foram empregues de forma precária, tornando-o difícil de transitar em qualquer ocasião, sendo mais grave em período de chuvas onde as várias falhas como rachaduras ou buracos se enchem de agua e ocorre a formação de várias poças. O mínimo de estudo que tivera sido realizado antes da construção dos passeios, poderia ter amenizado e ou eliminado grande parte dos erros que ali se encontram, tornando a construção mais econômica a longo prazo, não sendo necessário gastos em reformas e todas as variáveis recorrentes, desnecessárias se fosse construído de forma mais inteligente e sustentável, respeitando a legislação de construção de calçadas.

\section{Resultados e discussões}

Após aplicação das soluções propostas e medidas de segurança, foi possível debater o caso apresentado juntamente com o resultado da pesquisa. Nesta a qual apresentemos panoramas gerais da situação que se encontra as calçadas de Teófilo Otoni. Em seguida elaborou-se no trabalho soluções e sugestões para melhora a qualidade dos passeios da cidade, juntamente com uma série de outras cidades que compõem o espaço urbano brasileiro.

Pela pesquisa realizada, foi observado a importância de um passeio sustentável e padronizado e o quanto ela torna a vida da população mais confortável e segura. Assim conscientizando que a área da engenharia civil pode abranger muito além de construções de casas, prédios e grandes viadutos, pois, nem tudo que é grande, surtirá tanto efeito quanto a uma obra de uso bem feita e prol do bem estar da sociedade. 
Certamente é possível aplicar o uso de Resíduos de Construção e Demolição (RCD) para a confecção dos passeios, sendo este método uma alternativa de grande potencial econômico, ambiental e social. Esse novo material permite um aumento na produção de novos materiais sem a necessidade de extrair grandes volumes dos recursos naturais. Outro fator importante está relacionado com a instalação de usinas de resíduos, abrindo oportunidade no mercado através de produtos com qualidade, eficiência e de menor impacto no todo.

E quando o deslocamento não é agradável, as pessoas buscam os meios mais fáceise rápidos, que são os veículos e outros meios de locomoção pelas ruas, aumentando a poluição do ar, gerando custos e entupindo mais as já congestionadas vias de trânsito, elevando os níveis de estresse da população e sobrecarregando as vidas diárias da população.

\subsection{Possíveis soluções e adequação}

Tendo em vista que as duas ruas apresentam problemas semelhantes em suas calçadas, foi proposto algumas alternativas, conforme a Tabela 1.

Tabela 1 - Relatório da área estudada

\begin{tabular}{|c|c|c|}
\hline ASPECTOS & CAUSAS PROVÁVEIS & SOLUÇÃO \\
\hline $\begin{array}{l}\text { Deterioração do passeio } \\
\text { por Raízes. }\end{array}$ & $\begin{array}{l}\text { Escolha inadequada das } \\
\text { árvores, ausência de } \\
\text { canteiros e valas para o } \\
\text { recebimento das árvores. }\end{array}$ & $\begin{array}{l}\text { Eliminação das raízes ou das } \\
\text { árvores; Recuperação da } \\
\text { calçada; plantio de árvores } \\
\text { adequadas para áreas } \\
\text { urbanas em manilhas. }\end{array}$ \\
\hline $\begin{array}{l}\text { Obstrução do passeio } \\
\text { com entulhos e lixos. }\end{array}$ & $\begin{array}{l}\text { Falta de conscientização } \\
\text { e punição das pessoas } \\
\text { que descartaram os } \\
\text { materiais da forma } \\
\text { inadequada. }\end{array}$ & $\begin{array}{lr}\text { Conscientização } & \text { da } \\
\text { população, fiscalização do } & \text { dos } \\
\text { poder público, Punição do do } \\
\text { responsáveis, limpeza do } \\
\text { local. }\end{array}$ \\
\hline Ausência do passeio. & $\begin{array}{l}\text { Ausência da fiscalização } \\
\text { e inobservância do }\end{array}$ & Construção do passeio. \\
\hline
\end{tabular}




\begin{tabular}{|c|c|c|}
\hline & governo municipal. & \\
\hline $\begin{array}{l}\text { Desgastes, peças soltas } \\
\text { e remendos. }\end{array}$ & $\begin{array}{l}\text { Ausência de manutenção } \\
\text { e qualidade de execução. }\end{array}$ & Recuperação total do trecho. \\
\hline Desníveis irregulares. & Má execução. & $\begin{array}{l}\text { Reorganização e adequação } \\
\text { do passeio. }\end{array}$ \\
\hline $\begin{array}{l}\text { Ausência e desgaste da } \\
\text { sinalização das calçadas. }\end{array}$ & $\begin{array}{l}\text { Ingerência do poder } \\
\text { público e falta de } \\
\text { manutenção. }\end{array}$ & $\begin{array}{l}\text { Implantação e recuperação da } \\
\text { sinalização. }\end{array}$ \\
\hline $\begin{array}{l}\text { Inconstância e } \\
\text { variabilidade do } \\
\text { acabamento do passeio. }\end{array}$ & $\begin{array}{l}\text { Ausência de material e } \\
\text { da fiscalização do } \\
\text { município, má gestão e } \\
\text { imperícia da obra. }\end{array}$ & $\begin{array}{l}\text { Elaboração de um } \\
\text { desenho universal. }\end{array}$ \\
\hline
\end{tabular}

Fonte: Tabela dos autores

Segundo as normas NBR 9.050 (2015) e a NBR 16.537 (2015) e o no Decreto Municipal 3.057 de 2015 da prefeitura da cidade de Goiânia/DF, apresentam um modelo adequado, acessível e sustentável de uma calçada, conforme a figura 1. Além disso, é preciso seguir uma série de procedimentos:

- As calçadas devem possuir um dimensionamento adequado, seguro e confortável;

- Os pisos das calçadas devem ser regulares, estáveis e antiderrapantes, construídos com qualidade e de fácil deslocamento para todos os que dela necessitam;

- Os passeios precisam ter uma drenagem eficiente, com intuito de evitar alagamentos e dificuldades na locomoção dos pedestres;

- Devem ser acessíveis, sem desníveis e irregularidades, sempre seguindo os padrões em normas e regulamentos;

- As calçadas devem estar sinalizadas e possuírem um espaço agradável e segura para as pessoas. 
Figura 1 - Vista geral de uma calçada adequada de acordo com o Decreto Municipal 3.057/2015 (Goiânia,

DF), NBR 9050:2015 e NBR 16537:2015.

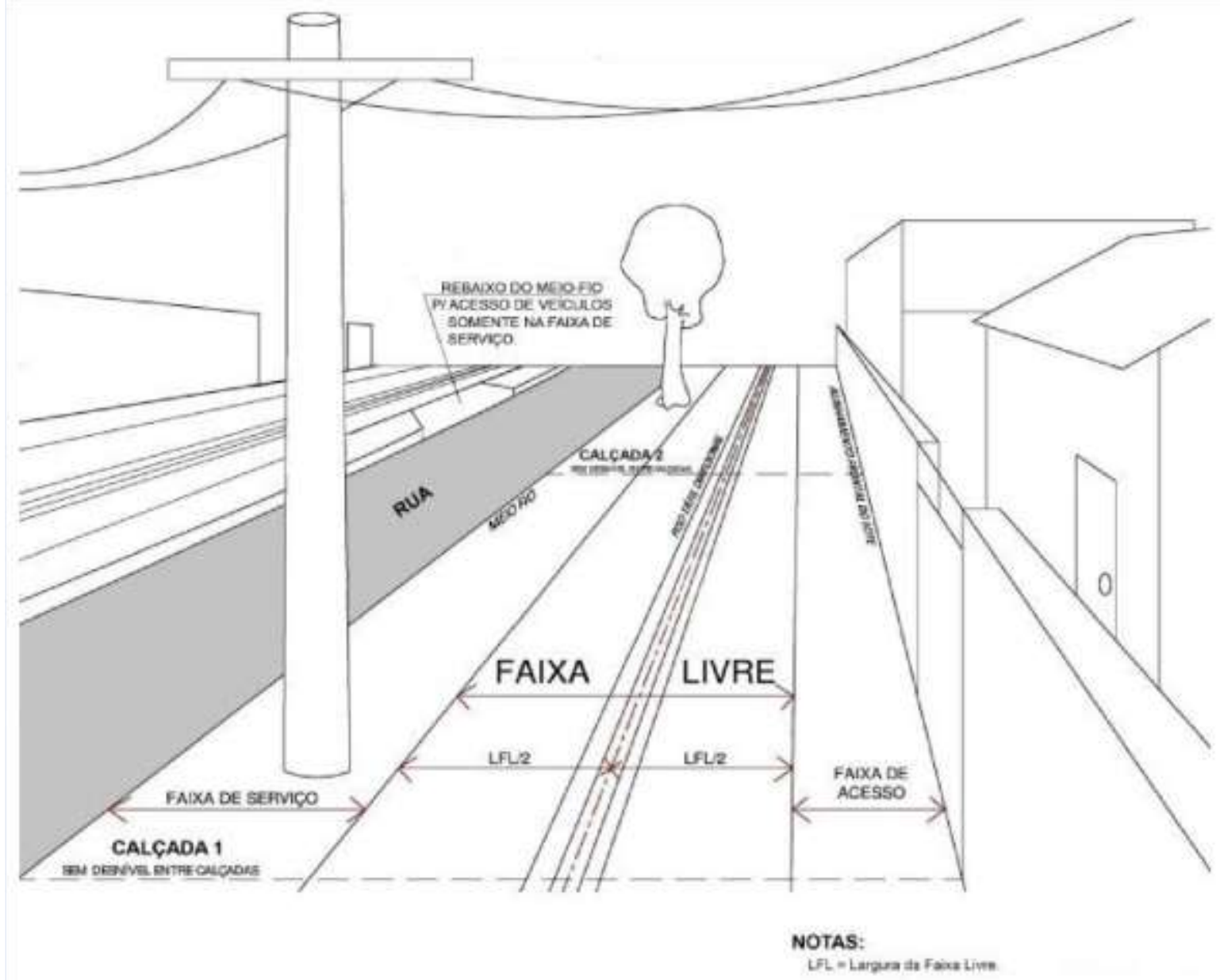

Fonte: Adaptada pelos autores. Disponível em: <https://tetraconind.com.br/blog/guia-completo-nova-lei de-calcadas-de-goiania/>. Acesso em: 02 de junho de 2020.

\section{Conclusão}

A engenharia tem o dever cívico de estar em contínuo desenvolvimento, buscando tornar a vida da população cada vez mais agradável, segura e em harmonia com a sustentabilidade, e uma das áreas mais importantes são os passeios. Através dos quais a maioria da população transita pelos centros urbanos e bairro onde reside ou trabalha.

Os dados coletados apontam que o trecho necessita de reparos imediatamente, pois apresentam risco a segurança das pessoas que transitam pela 
área. Para isso, é preciso que o poder público municipal desenvolva as políticas urbanas de mobilidade e acessibilidade, além de fiscalizar e acompanhar toda a fase de execução e manutenção. Compete também ao município elaborar políticas educativas para que a população contribua para a melhoria do sistema urbano.

\section{Referências}

ALMEIDA, Carlos Eduardo Santos; OLIVEIRA, Gladys Menezes. A nova política de mobilidade urbana: um caminho para o desenvolvimento sustentável das cidades brasileiras. Ideias e Inovação-Lato Sensu, v. 2, n. 1, p. 17-26, 2019.

ARAÚJO, Lucas Pereira de et al. Mobilidade urbana sustentável e inclusiva: o cadeirante e a calçada na área central de Uberlândia. 2019.

BRASIL. Lei $n^{\circ}$ 9.503, de 23 de setembro de 1997. Institui o Código de Trânsito Brasileiro. Diário Oficial da União, Brasília, DF, 1997.

BRASIL. Lei $\mathrm{n}^{\circ}$ 12.587, de 3 de janeiro de 2012. Institui as diretrizes da Política Nacional de Mobilidade Urbana; revoga dispositivos dos Decretos-Leis nos 3.326, de 3 de junho de 1941, e 5.405, de 13 de abril de 1943, da Consolidação das Leis do Trabalho (CLT), aprovada pelo Decreto-Lei oㅜ 5.452, de 1ำ de maio de 1943, e das Leis ํㅗ 5.917 , de 10 de setembro de 1973, e 6.261, de 14 de novembro de 1975; e dá outras providências. Diário Oficial da União, Brasília, DF, 2012.

CARLETTO, Ana Claudia; CAMBIAGHI, Silvana. Desenho Universal: um conceito para todos. São Paulo: Instituto Mara Gabrilli, 2008. Disponível em: https://www.maragabrilli.com.br/wp-content/uploads/2016/01/universal_web-1.pdf>. Acesso em 10 de junho de 2020.

COSTA, Hugo Oliveira. Proposição de metodologia avaliativa de calçadas: um estudo das calçadas da Esplanada dos Ministérios. 2019. 
FRAGA, Kéllen Tolotti et al. Avaliação da sustentabilidade ambiental da Universidade de Passo Fundo. 2011.

GHIDINI, Roberto. A caminhabilidade: medida urbana sustentável. Revista dos Transportes Públicos-ANTP. São Paulo, v. 33, 2011.

JUNIOR, Francisco Rodrigues de Sousa; FLORO, Elisângela Ferreira. Acessibilidade e Envelhecimento: Análise de Calçadas e Passeios Públicos no Município de Juazeiro do Norte.

Revista Científica Multidisciplinar Núcleo do Conhecimento. Edição 06. Ano 02, Vol. 01. pp 439-455, setembro de 2017

MiChELETtO, T. M. G. P. O risco do idoso pedestre nas vias urbanas. Companhia de engenharia de tráfego, São Paulo, notas técnicas, p. 1-13, 2011.

NÓBREGA, Fábio Augusto Rodrigues et al. Infraestrutura Urbana: infraestrutura e o crescimento populacional no Brasil. Caderno de Graduação-Ciências Exatas e TecnológicasUNIT, v. 1, n. 2, p. 19-25, 2013.

PREFEITURA DE GOIÂNIA. Manual da calçada sustentável. Goiânia, 2012. Disponível em: <http://www.cbic.org.br/boaspraticasnaconstrucao/boas_praticas/Boas\%20Práticas\% 20\%20Consciente/Boa\%20Prática\%20Consciente\%202/calcada_sustentavel.pdf>. Acesso em: 01 de junho de 2020.

PREFEITURA MUNICIPAL DE TEÓFILO OTONI. Lei $n^{\circ} 5.892$, de 10 de dezembro de 2008.

Dispõem sobre o plano diretor participativo do município de Teófilo Otoni. Câmara Municipal. Teófilo Otoni, MG, 2008. 
PREFEITURA MUNICIPAL DE TEÓFILO OTONI. Lei complementar $\mathbf{n}^{\circ} \mathbf{1 1 3}$, de 9 de agosto de 2016. Dispõe sobre o Código de Obras e Edificações do Município e dá outras providências. Câmara Municipal. Teófilo Otoni, MG, 2016.

PREFEITURA MUNICIPAL DE TEÓFILO OTONI. Lei complementar $\mathbf{n}^{\circ} \mathbf{1 1 4}$, de 9 de agosto de 2016. Dispõe normas e condições para parcelamento, ocupação e uso do solo urbano no Município de Teófilo Otoni e dá outras providências. Câmara Municipal. Teófilo Otoni, MG, 2016.

SANTOS, Maria Amanda da Silva et al. Análise da mobilidade urbana em cidade de pequeno porte-estudo de caso: região que liga o centro ás principais ruas da cidade de Caraúbas-RN. 2019.

THOMAZ, Ercio. Tecnologia, gerenciamento e qualidade na construção. São Paulo: Pini, 2001.

VIEIRA, Rafaela; MORASTONI, Raíza. Qualidade das calçadas na cidade de Camboriú/SC: em busca da acessibilidade e mobilidade sustentável para área turística. Revista Brasileira de Pesquisa em Turismo, v. 7, n. 2, p. 239-259, 2013.

UEDA, Thiago Minoru. Identificação e diagnóstico de patologias: um estudo de caso. 2017. 